\title{
Population Policy and the Demographic Transition: Performance, Prospects, and Options ${ }^{1}$
}

\author{
Paul Demeny $^{2}$
}

In countries that comprise the majority of the world's population, the demographic transition has now reached its putative endpoint: a state marked by low fertility and low mortality. It is expected that the rest of the world's countries are headed in the same direction, prompted by modernizing social change and nudged also by looming physical constraints. What were the roles of deliberate policies, and in particular of policies aimed at affecting fertility, in prompting this momentous transformation? What lessons might that experience hold for shaping population policies in the contemporary world, and shaping them in the future, after transitions have been completed? The discussion below seeks to give at least some partial answers to these questions.

\section{Before the transition: Population change without policy as a driver}

In traditional societies, fertility and mortality are high. In modern societies, fertility and mortality are low. In between, there is demographic transition. Few demographers would be satisfied with this lapidary definition of the transition, yet it states the key determining parameters of that process. But it does not explain its driving forces and of course does not inform about the particular demographic characteristics of the post-transition state.

The pre-transition era's essential demographic characteristics are reasonably well known. Although estimates of population numbers before about 1700 lack accuracy, it is certain that for large population aggregates over long periods of time - such as the preceding one or two millennia - the average rate of growth was extremely low; positive yet barely distinguishable from zero. It is then difficult not to attribute an underlying collective rationality to the behavioral patterns that yielded fertility levels that generated such long-run near-stationary equilibrium. Lower fertility would have led to population decline. To the extent that higher fertility would have been possible, the control mechanism keeping growth rates in check described by Malthus — an upward adjustment of mortality — would have been triggered. This mechanism is self-regulated: to talk about population policy in the sense as the notion is understood todayconscious government efforts to influence the determinants of population change-would be plainly anachronistic.

\footnotetext{
${ }^{1}$ This article appears in Demographic Transition and its Consequences, Ronald D. Lee and David Reher, eds., Supplement to vol. 37 of Population and Development Review, The Population Council, New York, 2011.

2 Paul Demeny is Distinguished Scholar, The Population Council, New York.
} 
Rulers of any political unit always had, however, an obvious a stake in the size and composition of the population over which they had authority, hence an incentive to try to steer demographic change in a desired direction. Greater numbers tended to connote greater wealth and power, at least for those at the apex of the social pyramid. Populationist sentiment had prevailed among rulers throughout history, evidenced by territorial expansion and conquest, and often also by openness to and encouragement in admitting people from the outside to territories controlled by the rulers. But in traditional societies the leverage of the weak pre-modern state over natural growth, and especially over the crucial and variable of fertility, was necessarily limited. The dominant influence setting the patterns of reproduction was located, instead, in a deeper layer of social interaction. Births, the key element affecting population change, are produced by individual couples - seemingly an intensely private affair yet one in which the immediate kin group and the surrounding local society in which that group is embedded have a material stake. All societies, if at varying degrees, grant a measure of self-sovereignty to their members. An individual has certain rights over his or her direction in life. But this is always subject to constraints, not only biological but also social. Well before rights and obligations are formally codified in legal terms, they are established through spontaneous social interaction-a selforganizing process. Restrictions on freedom to act take the form of social expectations and pressures that individuals can ignore only at considerable personal costs to themselves. Typically, there was a strong expectation that men and women should marry and have children. Parental and kin obligations in the matter of bringing up children were well understood by all adults and informally enforced by the community. In most traditional societies there was an expectation that children are to be born to married couples only; that a husband is obligated to support his wife and his children; and that he can expect reciprocal services from them. And informal rules shaped by community interest tended effectively to regulate the entry of foreigners.

The fabric of such demographically relevant behavioral expectations, supported by internalized personal norms and buttressed by religious injunctions, was a product of social evolution; how effective such institutions were became an important determinant of societal success. As a classic statement of Alexander Carr-Saunders, a prominent British demographer of the interwar years, asserted, groups practicing the most advantageous customs would have an advantage in the constant struggle between adjacent groups over those that practiced less advantageous customs. Few customs can be more advantageous than those that result in a number of persons the members of the group consider as one serving their best interest. Thus in the traditional society there would grow up an idea that it was the right thing to bring up a certain number of children, and social behavior yielding that number on the average would be enforced by a web of informal but effective expectations and pressures.

Given the harsh biological and economic constraints pre-modern societies invariably experienced, that "desirable number" presupposed fairly high fertility: high enough to provide a sufficient margin of safety over mortality. Successful societies - societies that survived to the dawn of the 
modern era - thus obeyed the biblical injunction to be fruitful and multiply, even though such multiplication as a matter of necessity was very slow. But traditional demographic regimes resulting from spontaneous social interaction achieved their modest population growth rates at varying levels of fertility and mortality. Early modern Western Europe succeeded in maintaining a relatively low average level of mortality by means of keeping birth rates low, primarily by means of a fairly high average age of marriage and substantial proportions that remained permanently single. A contrasting pattern, prevailing in much of the rest of the world, combined early and universal marriage and a consequent higher level of fertility with death rates that were also higher. With respect to the rate of population growth, these different combinations of birth and death rates in traditional societies were closely similar. The potential for rapid population growth that might be triggered by a fall of mortality was, however, much higher when the premodern equilibrium was the result of a combination of high mortality and high fertility.

\section{Rationale for population policy}

The rise of effective state formations in the West brought about the credible promise of realizing a better material life for large masses of people. The state increasingly came to be seen as an institution created by the voluntary association of the individual members of a given society to further their interests. The central function of the state was to produce public goods-goods that individuals cannot secure for themselves. The US Constitution, promulgated in 1789, articulated the key items among such goods concisely and with the ambition of conveying universal validity. The aim of the Union formed by the People was, in the words of the Constitution's Preamble, to "establish Justice, insure domestic Tranquility, provide for the common defence, promote the general Welfare, and secure the Blessings of Liberty to ourselves and our Posterity." In pursuing such goals, regulation of immigration into a state's territory is clearly defined as a public good, thus delineating a particular role for population policy. And aggregate fertility may also be construed as a public good, if its level as determined by spontaneous social interaction is considered too high or too low as assessed with reference to the collective interest.

The potential role of the state in regulating immigration is straightforward: individuals wishing to restrict or promote it cannot set up their own border patrols or issue entry visas. Individual preferences in the matter, however, are likely to differ. It is the task of the government to weigh and reconcile conflicting individual desires and come up with a policy deemed the best under the accepted rules of the political decision-making process.

To claim a role for the state in the matter of fertility is evidently far more problematic. Additions to the population are the result of a multitude of individual decisions concerning childbearing. Within the constraints of their social milieu, these decisions reflect an implicit calculus by parents about the private costs and benefits of children to them, including consideration of the interests of the children themselves. But neither costs nor benefits of fertility are likely to be fully internal to the family: they can also impose burdens and advantages on others in the society. 
Such externalities, negative and positive, represent a legitimate concern for all those affected. An individual's influence on the fertility of other families, however, is limited: there are no private markets offering preferred patterns of aggregate demographic processes to individual buyers. Remedying such market failure may then be attempted through intervention by the state so as to affect individual behavior in order to best serve the common good.

The earliest clear formulation of the population problem as a problem of coordination among individual preferences, hence establishment of the rationale for potential state intervention in the matter of fertility, was given by William Foster Lloyd, an Oxford mathematician and economist, in an essay published in 1833. In the spirit of the Malthusian concerns of his time, Lloyd noted the possibility of overpopulation even under conditions when all families have only the children they actually want and suggested the direction in which remedy ought to be sought. The simple fact of a country being overly populous, he pointed out, is not, of itself, sufficient evidence that the fault lies in the people themselves, or a proof of the absence of a prudential disposition. The fault may rest, not with them as individuals, but with the constitution of society, of which they form part.

Population policy should therefore strive toward institutions and incentive systems - a constitution of society - that provide signals to individuals guiding them to behave in harmony with the collective interest.

\section{The onset of demand-driven fertility transition}

The dawn of modernity was signaled by increases of agricultural productivity, permitting gradually diminishing death rates hence accelerating population growth. But that growth could limit the gains improved productivity would have permitted in terms of average standards of living. In his famous Essay, written one-third into the $18^{\text {th }}$ century, Richard Cantillon, one of the founding fathers of modern economics, devoted a chapter to this race between numbers and products. Is it "better to have a great multitude of Inhabitants, poor and badly provided, than a smaller number, much more at their ease?" he asked. That normative question was not answered by him, but he supplied a positive theory of population growth, highlighted in the elaborate title of his Chapter XV: "The Increase and Decrease of the Number of People in a State chiefly depend on the Taste, the Fashions, and Modes of Living of the Proprietors of Land." Thus, formulated for the dominantly agrarian society of his age, but with a bright future of general applicability, the demand theory of fertility was born. The size and growth of the population, Cantillon held, reflects how people wish to spend their resources and what levels of living they consider acceptable for themselves and their families. He concluded that "the Increase of Population can be carried furthest in the Countries where the people are content to live the most poorly and to consume the least produce of the soil". 
Classic Malthusian theory considered the outcome of this race between growth in productivity and growth in population foreordained. As was posited in the Bible, "When goods increase, they are increased that eat them" (Ecclesiastes 5:11). Malthus agreed. He held that population has an inevitable tendency to grow exponentially and such growth eventually must nullify any economic gains. Rising mortality cuts population growth back to zero. The initial improvement is doomed to be temporary: for the great masses of people equilibrium is reestablished at subsistence levels of living.

Whatever the validity of this grim model of economic-demographic interaction in interpreting pre-modern population history, it was shown to be invalid for the two centuries that followed its formulation. The industrial revolution, set on its course in Western Europe by the harnessing of new energy sources and by an outburst of technological improvements in industrial production and transportation, brought rising standards of living, hence better health and falling mortality. Demographic transition, albeit destined to proceed with significant differences from country to country as to its timing, speed, and growth implications, was set into motion on its worldtransforming trajectory. In its long initial phase birth rates remained high or decreased only slowly, hence lower death rates spawned historically unprecedented rates of population growth. But the economy could grow even faster, accommodating the ever higher human numbers. On the global level, during the $19^{\text {th }}$ century population has multiplied by a factor of 1.8 , from about 900 million to slightly over 1.6 billion. In the $20^{\text {th }}$ century, with world population by 2000 passing the 6 billion mark, the global multiplier was 3.8. The expansion of the supply of food, the ultimate limitational factor in Malthusian theory, kept pace with, indeed well surpassed, the expansion of population, however rapid the latter turned out to be.

But could such expansion in a finite planet continue to keep up with continuing Darwinian dynamics? Replicating $20^{\text {th }}$ century growth in the $21^{\text {st }}$ would have produced a global population over 23 billion. Wouldn't that be Malthus redux? That is a question history will not put to test. Albeit with a time lag, the fall of mortality elicited decreasing birth rates. By the third decade of the $19^{\text {th }}$ century Malthus's own thinking has also evolved, leading him to a terse but lucid and profoundly significant formulation of a demand theory of fertility of his own. Improvements in the standard of living need not be followed, as it were by an iron law, by fertility-generated slipping-back to mass misery and rising mortality. He wrote: "From high real wages, or the power of commanding a large portion of the necessaries of life, two very different results may follow; one, that of a rapid increase in population, in which case the high wages are chiefly spent in the maintenance of large and frequent families; and the other, that of a decided improvement in the modes of subsistence, and the conveniences and comforts enjoyed, without a proportionate acceleration in the rate of increase" .

The possibility of such diametrically different responses to the stimulus of higher wages suggests a large element of indeterminacy in fertility behavior. To Malthus, the causes of these divergent responses were to be found in the circumstances, social and political, in which people lived-in 
particular, whether those circumstances hindered or rewarded planning for the future. From his analysis he derived a prescription for a population policy that would yield the hoped-for demographic outcome: "Of all the causes which tend to generate prudential habits among the lower classes of society, the most essential is unquestionably civil liberty. No people can be much accustomed to form plans for the future, who do not feel assured that their industrious exertions, while fair and honourable, will be allowed to have free scope; and that the property which they either posses, or may acquire, will be secured to them by a known code of just laws impartially administered. But it has been found by experience, that civil liberty cannot be secured without political liberty. Consequently, political liberty becomes almost equally essential.” (ibid.)

During the long nineteenth century — which may be thought of as stretching to the outbreak of the First World War - the politics in Europe and in its overseas offshoots favored, even if imperfectly, the development of institutional and legal frameworks in harmony with such principles. This, in interaction with economic and cultural changes shaped by the industrial revolution, created a milieu that fostered the prudential habits of parents, rendering the microlevel calculus of the costs and benefits of children increasingly salient. Rising demand for labor, including greater use of child labor, and rising income levels tended to sustain high fertility or even to stimulate it. But improving health conditions and lower death rates, literacy and education, rising material expectations and broadening opportunities for social mobility, the progressing emancipation of women and their increasing participation in the formal labor force, and the general patterns and less child-friendly circumstances of urban living soon pulled in the opposite direction. This was powerfully reinforced by some programmatic activities that were consistent with the limited role the liberal state claimed in managing the economy. Beyond establishing and maintain the rule of law and protecting property rights, these included programs providing better sanitation and promoting public health as well as projects aimed at improving basic infrastructure for transport and communication. Late in the $19^{\text {th }}$ century, state-organized arrangements for income security for the elderly started to be adopted, lessening and eventually largely eliminating reliance on children as a source of support in old age. In the increasingly complex economy the needed length of formal education for children grew longer. To relieve its costs directly falling on parents, the state, or local government, assumed a key role in financing public education. At basic levels, school attendance was made mandatory and labor laws were adopted that curtailed the employment of children. On balance, the costs of raising children borne by parents rose substantially.

Reflecting long-standing cultural values and religious injunctions, and contrary to laissez-faire principles, the liberal state generally banned the spreading of contraceptive information and the sale of contraceptive devices and made abortion illegal. Such restrictions typically remained in effect well into the twentieth century. But by all evidence, any upward pressure on fertility from these restrictions was swamped by diminishing parental plans for the number of children they 
wished to have, reflecting rising material aspirations, fears from loss of social status, and rational responses to signals from a competitive market economy in which large families became a disadvantage. During much of the $19^{\text {th }}$ century birth rates were slowly falling in France and in the United States, and by the turn of the $20^{\text {th }}$ century they were falling rapidly in virtually every country of the West. In many cases, rates of population growth fell also, despite continuing improvements in mortality and the temporary moderating effect of population momentum reflecting earlier higher fertility. In most countries of Europe this trend was reinforced by net outmigration, which both sending and receiving countries - notably the United States, Canada, and Australia - positively encouraged or at least permitted.

The effects of the institutions of the liberal state on fertility behavior thus brought about the prospect of a new demographic equilibrium in the West. Contrary to the original Malthusian formulation, that equilibrium could be consistent with continuing material progress: convergence to a stationary population at low levels of fertility and mortality, at a population size not necessarily optimal in an economic sense yet not conspicuously excessive in relation to the physical environment.

\section{New policy concerns for transition's pioneers}

The massive losses of life resulting from World War I and from the influenza pandemic in its immediate aftermath, and the sharp drop in the number of births during the war-years, were temporary disruptions in the steadily declining trends of fertility and mortality that characterized the prewar decades in the West. Those trends soon made it evident that there is no built-in guarantee that the sum total of individual fertility decisions will eventually converge to a point at which, in the aggregate, the rate of population growth will be exactly zero or fluctuate tightly around a zero rate. By the late 1920s demographers realized that fertility rates in several Western countries had fallen to such a low level that, in the longer term, natural increase would become negative. This trend became more accentuated and more general under the impact of the Great Depression. Some observers foresaw a "twilight of parenthood."

Just as excessive reproduction perceived in a Malthusian frame of mind called for corrective fertility-moderating public policies, in an increasing number of Western countries there were calls for corrective action achieving the opposite result: enhancing fertility so as to assure at least the simple maintenance of the already-achieved population size. In some countries the ban on contraceptives was tightened and the penalties on abortion were increased. These measures had little effect. Neither did, predictably, governmental exhortation appealing to families to have more children.

The most promising avenue for population policy seemed to be to use the instruments available to the state for redistributing income so as to reward demographic behavior considered socially desirable and to discourage contrary behavior. By the 1930s such pronatalist policies came to be 
fairly widely if tight-fistedly applied in low-fertility countries. Among Europe's emerging democratic welfare states, Sweden and France were pioneers in providing financial rewards and services in kind to families with children, especially to larger families. (Sweden, however, also allowed liberal access to contraception.) Similar policies were applied with greater vigor in fascist Italy and Nazi Germany.

Invariably, the proponents of such policies claimed some results in terms of birth rates somewhat higher than would have been expected in their absence. But the latter quantity is a hypothetical one, which introduces a necessary caution to such claims. More pertinently, when average fertility is low, the birth rate, or the TFR in any given year is an unreliable measure of long-run fertility. Couples have considerable latitude to time the birth of their children earlier or later, without affecting the number of children they ultimately wish to have. Logically, pronatalist policies seek to affect that lifetime total rather than aiming at temporary increases in the birth rate.

By the mid-period between the two World Wars, around 1930, Western fertility levels, countryby country, were typically near replacement level and often below it. The net reproduction rate was 0.71 in Austria, 0.74 in England and Wales, 0.75 in Germany, 0.86 in Sweden and France, and 0.94 in the United States. Relatively young age distributions temporarily still sustained positive rates of natural increase, but maintenance of the existing fertility levels clearly presaged eventual population decline. This radical transformation of the demographic landscape is well mapped by demographers and need not be elaborated here. The economic and social forces bearing on the micro-level calculus of the costs and benefits of reproduction that powered that transformation are also well understood and have been described by countless analysts essentially following and further refining the insights of Cantillon and Malthus.

Observed trends of fertility during the interwar years have thus clearly signaled the end of the demographic transition in the West. The criteria satisfying the definition given at the start of this article were either already met or their achievement seemed imminent. Both fertility and mortality were "low" - the latter index at least as reflected by the relevant measure: survival up to the upper limits of the childbearing age. But the implication of those low levels did not necessarily suggest the smooth attainment of a stationary state as envisaged in stylized textbook models of the demographic transition. Below-replacement fertility rates experienced in the 1930s demonstrated the possibility of an overshoot in the declining trend. And the possible workings of a spontaneous mechanism that would bring fertility back to equilibrium were far from evident. If the mature Malthus was right, that once the "character of the lower classes" becomes elevated, they will exercise restraint in reproduction because "they cannot acquiesce patiently in the thought of depriving themselves and their children of the means of being respectable, virtuous and happy," why could not such virtue and happiness be consistent with having on average less than two children surviving to adulthood? And could not "social capillarity" as perceived by Arsène Dumont result in below-replacement fertility? Indeed, demographers, like the most 
prominent French transition theorist, Adolphe Landry, foresaw a coming population decline. Landry argued that the end of the transition (he called it "demographic revolution") will be a long-term disequilibrium - one in which fertility levels sink below replacement for a long duration. Oswald Spengler predicted Europe's "appalling depopulation...that will last for centuries." Keynes, who in the early postwar years still worried about the "Malthusian devil," by the 1930s came to see the demographic future as one of stagnation or plausibly decline.

Such perspectives suggested that governments' indifference to population matters in the West will be replaced by policies seeking to counteract an undesired trend. Writing in the late 1940s, when the reappearance of low prewar birth rates was still the common expectation in the United States as well as in Europe, Frank Notestein contemplated the likely reaction: "Between now and the end of the century...many of the forces tending toward a reduction of family size are likely to continue in effect. On the other hand, we have yet to see a nation approaching a stationary population that did not launch strong measures to stimulate childrearing. I expect that efforts to increase births will be one of the major preoccupations of those concerned with social legislation in the Western world."

But this was not to be. After the war was over, the baby boom intervened, demonstrating the fallibility of population forecasts even when these are elaborated from a well-developed statistical base. The boom at least temporarily dispelled any talk about prospects of population decline, let alone discussion of action aimed at counteracting such prospects.

Policy ambitions in the domain of population became refocused, instead, on population change in countries in an earlier phase of the transition: countries characterized by steeply falling death rates and high levels of fertility, hence rapid population growth.

\section{International population policy: The drive to complete the transition}

In the countries that the United Nations categorizes as less developed, population policy issues attracted little attention until the middle of the twentieth century. Fertility remained high, more or less at its pre-modern level. Population growth was slowly increasing, however, as a result of improvements in mortality. Following the end of World War II, mortality decline accelerated greatly and as a result so did population growth. In 1950, world population was 2.5 billion. Some 1.7 billion of that was in countries classified as less developed, with an average annual birth rate of 44 per 1000 population - twice as high as in the more developed group. Unless a decline of the birth rate got underway fairly rapidly, an unprecedentedly large expansion of human numbers was inevitable.

Although the trigger of such population growth was a welcome development - falling death rates - growth rates that would double or even treble a population within a generation seemed a major obstacle to development and a potent generator of mass poverty. And the large and widening opposite-signed differentials between the more developed and the less developed 
countries in terms of population size and average income levels was seen as holding out the prospect of major dislocations and long-term instabilities within the international system. As a result, in the 1950s an intense debate started on what policies could reduce fertility in the less developed world. This policy debate was primarily Western, much of it American, just as the diagnosis of the problem itself had been. The proposals that emerged were to be applied in countries representing a large and growing share of the global population. Population policy became "international."

The West of course already had relatively low fertility, and with it much historical experience on why birth rates fell. Social science analysis was virtually unanimous in interpreting this experience. The explanation centered on the role of changing structural conditions of the economy, conditions to which micro-level units of the population tended to respond, in demographic as well as in other matters. Demand for smaller families was seen as the primary force determining birth rates; the means by which couples regulated their fertility was not unimportant, but seen as a distinctly secondary factor. If the demand was strong enough, fertility would be low, even if birth control technology was primitive. A transition to low fertility presupposed changing preferences, and such preferences were responses to market signals. If policy was to have an explicit role, it would be through reinforcing those signals.

In the experience of past fertility transitions, four components of the incentive structure seemed especially pertinent in discerning the prospects of fertility change in the developing world: the direct costs parents must incur in bringing up children; the opportunity costs of children to parents, that is, the earnings a couple (and especially the wife) must forgo because of children; the contribution of children to family income through labor services; and the contributions of children to parents' economic security in old age, in comparison to alternative sources of security.

Fertility declines when shifts in these components make family limitation advantageous to couples, overcoming cultural resistance supporting traditional behavior. Patterns of development generate that effect when at least some, but especially when all of the following conditions are fulfilled: social expectations and formal institutional arrangements place on parents the major financial responsibility for raising their own children, including much of the cost of education and health care; women have access to income-earning opportunities in the labor market, including jobs not easily compatible with childbearing and childrearing; social institutions make formal education (primary and early secondary) compulsory and effectively enforce school attendance; child labor is made illegal; effective legal guarantees of property rights, legal enforcement of private contracts, and the development of public and private insurance and pension schemes provide attractive and comparatively secure alternatives to children as a source of old-age security.

Social and institutional conditions that make such changes potent generators of fertility decline include the following: emphasis on personal economic contribution (rather than, for example, 
class status or political loyalty) as the primary factor determining a person's earnings, thus providing an incentive for increased investment in human capital; systems of promotion that provide opportunities for upward social mobility according to merit and tolerate downward social mobility; openness to outside influences that create rising expectations with respect to material standards of living; and emphasis placed not only on the rights but also on the social and economic responsibilities of the individual.

Some of the factors that prompted the fall of fertility in the West also became operational in the less developed countries as concomitants of economic and social change, not the least a precipitous fall in mortality, promising the expected results in fertility behavior. International conferences, for example the 1974 Bucharest conference on population, spelled out many of the essential socioeconomic developments necessary for fertility to shift from high to low levels. But assembling the instruments so identified into a coherent strategy of institutional-structural reforms, reforms justified also by demographic objectives, remained an elusive task. In promoting development, governments, encouraged by much international advice backed up by foreign aid allocations, came to see their roles not in harnessing the market, but replacing it in performing key developmental tasks through specific goal-oriented categorical programs. In the matter of population policy, the rapid postwar progress in the technology of birth control provided an appealing apparent short-cut for achieving fertility decline through programmatic means. Markets, it was held, could not be relied on to bring that technology to those wishing to practice birth control. Governments could, instead, organize free delivery of birth control information, and provide effective means for preventing births to all those, primarily (it was assumed) women, who wished to plan their families. Surveys indicated that there existed a substantial latent demand for such services. Satisfied customers, in turn, would serve as role models, bringing new clients to the program.

By the mid-1960s, in programmatic terms the international population policy debate on the relative importance of demand versus supply was essentially decided in favor of the latter. The existence of demand for fewer births was taken for granted, but supply of contraceptives and ability to home-produce birth control were lacking. For the next quarter-century, population policy in the developing world became essentially synonymous with family planning programs.

Financial and administrative limitations within developing countries were seen as necessitating heavy involvement of foreign assistance in launching and sustaining family planning programs. Although donor countries' own domestic experience in this area was practically nonexistent, such aid, justified by the seriousness of the "population problem" (a problem whose severity was defined in terms of aggregate indexes of population growth), was readily forthcoming, partly in the form of bilateral assistance and partly through international aid institutions.

The cost of birth control technology was, in itself, relatively modest. But sustaining an effective delivery service did represent significant claims on scarce human and material resources. 
Declared demand for birth control does not necessarily translate into effective willingness to practice it: conflicting desires may interfere. Perceived weakness of latent demand, or "unmet need," was reflected in the requirements that programs were supposed to satisfy if they were to be successful. These typically included such items as, as spelled out by a director-general of WHO, "doorstep accessibility of quality services," "broad choice of contraceptive methods," "forceful IEC [information, education, and communication] programs," "sound financing strategies," "sound management with proper logistics," "evaluation systems," "a continuous process of strategic thinking, planning and management," and "staff leadership for program parameters".

This internationally approved and exported programmatic approach was justified by the sluggish interest in "population control" aid recipient governments commonly exhibited. As a remedy, it was felt, an organizational machinery had to be set up by outside experts, and to keep the machinery going it had to be oiled by foreign aid. But that approach seldom sparked local ingenuity, innovation, and enthusiasm. Such dynamism, as history in other fields of developmental endeavor tends to demonstrate, is most vigorous if home-grown by local elites, nurtured by observing other societies' successes and failures and fueled by a local-favored mixture of admiration, envy, irritation, frustration and contempt, intention to imitate yet determination to be different and to do better than the original model and to catch up and to overtake and surpass. And the model is seldom an organizational chart drawn up by international experts: it has more to do with getting acquainted with foreign products and technologies, studying statistics and watching foreign films and reading foreign fiction and observing tourists and coming home from a study year abroad and deciding that traditional ways of behaving are not compatible with modern ways of living and getting rich and determination that things at home must change. (This no doubt rudimentary characterization of reforming instincts involved has its even more important micro-level equivalent, prompting grass-roots changes in thinking, attitudes and preferences and leading to action to change fertility behavior.) Apart from China, whose population policy was fully home-grown, although with unsuspecting intellectual godfathers from far-away lands, population policies-government-organized family planning programs - in the developing world in the last third of the $20^{\text {th }}$ century tended to be transplants of a very different model.

The effectiveness of family planning programs in reducing fertility remains a matter of controversy. According to international guidelines, programs recruit their clients on a strictly voluntary basis. By accepting the service voluntarily, the individual acceptor demonstrates that she (or, sometimes, he) values that service. But some of the more successful programs, notably in Asia, tended to increase acceptance by often heavy-handed methods of persuasion (as, for a brief period in India), and (in the especially important case of China), by administrative fiat backed by legal sanctions. Where fertility fell in less developed countries with active family planning programs, it is typically found that program-provided free services account for a large 
percentage of those practicing contraception. This non-surprising result is then often taken as an indicator of success in reducing aggregate fertility. But what would have happened in the absence of the program is conjectural, hence routinely ignored. Some less developed countries that lacked government programs also experienced major falls of fertility: Brazil is a conspicuous example. Similarly, if programs had seemingly only minor success in reducing fertility, this could be taken as evidence that the program was inadequately financed, organized, and managed: greater efforts would have led to better results.

Family planning programs as they were commonly conceived had a strong resemblance to health programs. But given the special priority accorded to family planning services in foreign assistance, typically they were organized as a separate "vertical" program, or kept administratively distinct within the broad health program. The justification for such treatment was that while acceptors of family planning services are recruited because the program satisfies their individual need, the program also serves a national developmental need by helping to reduce aggregate population growth, hence deserves priority. Once a family planning program is organized, its managerial and professional cadres form a natural advocacy group strongly motivated to secure the program's sustenance. Invoking the public interest in lowered fertility, as distinct from simply serving the needs of the clients of the program, has long served as a key supporting argument in that endeavor.

Over time, this developmental prop has eroded. This was in part a result of criticisms of the intrinsic scientific merit of the argument. Even when outside financing for the programs were abundant, little attention was paid to exploring and understanding the relationship between population dynamics and economic and social change. The link between these factors was taken as self-evident: population growth takes out a big chunk from the growth of income per capita or even entirely wipes it out. This is a primitive formulation of a complex matter, but seemed to serve its purpose. But when developing economies can grow fast in terms of national income as conventionally measured - at a clip of five percent or more per year - the rationalization loses force. Over time, erosion of support was also a reflection of the extensive decline of fertility that has occurred, a decline often attributed to the success of the family planning programs themselves. On the eve of the 1994 International Conference on Population and Development, a review, considered highly respectful of the importance of fertility decline for successful development, reached the guarded conclusion that the data on the subject "mostly support the view that rapid population growth in poor countries under conditions of high fertility is inimical to many development goals" — with stress on the qualifying words "mostly," "high fertility," "many development goals," and "rapid," and with the last-mentioned term defined as "in excess of 2 percent annually". By that time, among world regions, only Africa and West Asia had a population growth rate meeting that criterion.

Accordingly, the development rationale of family planning programs was gradually dropped and was replaced by the argument that the programs satisfy important health needs and help people 
exercise a fundamental human right. The Cairo conference formalized this shift: even though the name of the conference for the first time included a reference to development, scant attention was paid to that concept. Family planning programs were redefined, instead, as reproductive health programs, responding to a broader range of women's health needs, such as prevention of unsafe abortions and sexually transmitted diseases, including HIV/AIDS. But beyond this, new emphasis was put on some requirements that would contribute to women's empowerment: reduction of infant and maternal mortality, improvement in girls' education, and women's opportunities for employment and political participation. Although the connection was not highlighted, these are conditions that are likely to help reduce the birth rate through stimulating the demand for smaller family size. The Cairo conference, in effect, reverted to some key elements of a demand strategy for reducing birth rates.

The future of family planning service programs is thus left in a somewhat tenuous status. Without invoking a collective interest in a wider practice of birth control, it is not clear what level of priority should be accorded to such programs as just one part of publicly financed health programs, or indeed relative to many other social welfare programs that also serve demonstrable human needs. Not surprisingly, there is growing respect given in national policy debates to suggestions to rely on the market in enhancing access to contraceptives and to provide program services on a fee-for-service basis. The spectacular rapidity of the spread of wireless methods of communication was driven by felt needs, not on free distribution of cell phones and forceful public IEC programs on how to use them. Rapid diffusion of contraceptive technology could rely on the analogous mechanism of demand eliciting supply, provided that demand was strong enough.

Yet slighting the significance of the connection between population dynamics and development is not warranted. Among numerous ramifications of the benefits of slower population growth, by the 1990s characteristics of the age distribution and changes in it received renewed emphasis from a number of economists. The transitional period, when the share of the age groups in the productive ages are especially high-because of lowered birth rates in the preceding decades have thinned out the numbers of the very young, and because population aging has not yet heavily increased the numbers of the elderly - came to be seen as an uplift to development, at least in those countries well enough organized to capture the "demographic dividend" offered by this temporary peculiarity of the age distribution. East Asian development is presumed to demonstrate this benign demographic effect. Where fertility decline is still laggard, its policyinduced acceleration thus promises measurable if temporary potential economic benefits.

Perhaps more significantly, if more controversially, economic thinking in the early $21^{\text {st }}$ century may be said increasingly to exhibit a distinct Ricardian hue. Resource constraint, and within it especially environmental constraints, faced by a global population now well exceeding 6 billion and heading toward 9 billion by mid-century (the UN's "low" and "high" population projection variants bracket that latter figure between 8 and 10.5 billion) are seen as potentially highly 
problematic. Can the high consumption levels attained in the rich countries become a characteristic of populations that are still relatively poor, and if so, with what social, economic, and geopolitical effects? Optimists see all countries proceeding on an upward economic growth trajectory, albeit with time lags and differential speeds. According to this view, a world with 9 billion inhabitants can eventually accommodate everybody in material comfort; indeed, some day Nepal should become as rich as Switzerland is today, while Switzerland, too, will continue its progress to even higher standards of living. Cross-sectional income differences-between countries, and within countries between social strata - are less important than the overall upward developmental dynamics. And such dynamics is both achievable and is certain to moderate and eventually stop, and even reverse, the growth in global population numbers. Generalizing from past trends, the relationship between wealth and wealth-generated problems, for example, environmental pollution, appears in this optimistic outlook as tracing a Kuznets curve: first a rise in pollution, then a leveling-off, followed by steady improvement. Other informed observers dismiss this view of world economic and population dynamics as Panglossian. They see the $21^{\text {st }}$ century as a time when the combination of growing material consumption per capita with already attained and still increasing population numbers is bound to clash with the globe's biophysical limits. And the limits themselves may be adversely affected by the product of human numbers and per capita consumption, as is signaled by forecasts of global climate change. Competition for resources and darkened prospects for steady economic growth, especially in countries that are still poor in social and human capital and short of special natural resources, suggest a 21thcentury world characterized by sharpening domestic economic and social problems (plausibly also including stalling fertility transitions) and political instability in many countries, with corresponding potential dire consequences for international conflicts. Pessimistic scenarios would then call for renewed recognition of population growth as a problematic element in the overall developmental dynamics and for a re-thinking of policy approaches promising appropriate remedies.

\section{Beyond the transition: Policies confronting below-replacement fertility}

During the second half of the twentieth century, debates about population policy, and consequent programmatic action, were centered on the issue of rapid population growth in the less developed world. Toward the end of this period, however, a quite different demographic phenomenon has begun to attract increasing attention: aggregate fertility levels that are inadequate for the long-run maintenance of the population. Analytically, the potential population policy issue raised by below-replacement level fertility is identical to the problem inherent in fertility levels that generate rapid population growth: it is caused by the disjunction between the sum total of individual reproductive decisions and the collective interest in a long-run demographic equilibrium. But this time, individual aspirations imply decreasing population numbers. The syndrome, as was noted above, is not entirely novel: it was detectable in fertility trends in the West, especially in Europe, in the 1920s and 1930s, and in some instances, notably in France, 
even earlier. But in the decades immediately following World War II, the baby boom seemed to make the issue of low fertility moot. Indeed, by any historical standard, population growth was rapid during the second half of the twentieth century even in the developed world. Europe's population, for example, grew during that period from 550 million to about 730 million.

The baby boom was, however, a temporary interruption of the secular downward trend in fertility. By the 1970s, the net reproduction rate was at or below unity in most countries in Europe and also in the United States. In the US fertility stabilized at or very close to that rate, but in Europe fertility continued to decline. By the beginning of the twenty-first century, the average total fertility rate in Europe was 1.4. Such a level, if maintained indefinitely, would result in a population loss of one-third from generation to generation, that is, roughly, over each period of some 30 years. In a dozen or so countries, notably in Southern, Central, and Eastern Europe, period fertility rates were at low levels without historical precedent for large populations. If continued, in the absence of large compensatory immigration this would not only lead to rapid population decline but also result in very high proportions of the population at old ages. It might be expected that in the affected countries such prospects would cause not only concern, but also prompt vigorous remedial policy action.

Bye and large, however, this response has not been evident. Most governments as well as the general public tend to view below-replacement fertility with an equanimity quite unlike the alarmed reaction that the same phenomenon elicited when it first emerged between the two World Wars. And introduction or at least advocacy of explicitly pronatalist policies, common in the 1930s, are conspicuous by their absence. There are a variety of reasons explaining this indifference.

First, the preeminent population issue confronting policymakers in the post-World War II period was rapid global population growth. Programs aimed at moderating fertility in the developing world received assistance and encouragement from the rich, low-fertility countries. Although the rationale was modified over time, such assistance and encouragement have continued, as indeed substantial further population increase in the less developed countries is still anticipated in the early decades of the twenty-first century. Even though population issues tend to be sui generis, reflecting differences in demographic behavior country-by-country, there was, and remains, a perceived dissonance between fertility-lowering assistance to other countries and engaging in action at home serving the opposite aims. Faulty logic notwithstanding, the international terrain has not been favorable for domestic pronatalism.

Second, the natural rate of increase - the difference between the number of births and the number of deaths - is still positive in many of the countries with fertility well below replacement. In the instances when the number of deaths exceeds the number of births, the loss still tends to be marginal. This is the result of age distributions - reflecting past fertility and mortality and notably the effects of the postwar baby boom - that still favor population growth or moderates 
population decrease. While this momentum effect is temporary, the longer-term implications for population decline and population aging are only dimly perceived by the general public and provide an excuse for inaction on the part of policymakers.

Third, when those longer-term demographic effects are understood, a calmer attitude still prevails. There is an inclination, reinforced by increasing concern with the quality of the natural environment, to regard a degree of demographic "decompression" as a not necessarily unwelcome prospect, especially in countries with an already dense population. And it is assumed that the economic and social disadvantages that might be imposed by a declining populationpopulation aging, intergenerational transfers, slower economic growth, industrial restructuringcan be effectively dealt with through institutional adjustments and social policy measures other than measures aiming for a higher birth rate. A demographic policy often regarded as potentially helpful in this regard is encouragement of immigration. That willing immigrants are available to compensate for low birth rates is taken for granted - a realistic assumption in high-income countries. But the underlying assumption behind this thinking is that the shortfall of fertility from replacement level is moderate and compensatory immigrant inflows are correspondingly small.

Fourth, there is a vague expectation that the population decline, impending or already begun, will in due course trigger corrective homeostatic mechanisms, leading to a spontaneous rebound in the level of fertility. Another baby boom may not be in the offing, but fertility may rise sufficiently to once again reach or at least approximate replacement level. Governments, it is assumed, would be ill-advised unduly to interfere with this natural process by trying to increase birth rates and then seeking to fine-tune them at the desirable steady-state level. According to this view, a laisser-faire fertility policy is justified since, apart from broad upper and lower limits, governments are not competent to determine what constitutes an optimal fertility rate, or growth rate, or population size in any given year, decade, or even longer time interval. Partial recoveries of birth rates in many low fertility countries in the first decade of the $21^{\text {st }}$ century give added credence to this hopeful stance. The influential UN medium population projections support this optimistic outlook. They stipulate a slow but steady recovery of fertility rates from present-day low levels. By around 2050, the assumed TFR is typically about 1.85 or very near to it.

Finally, even if the will were there, there is a paucity of effective pronatalist policy instruments. Exhortation from governments is not a promising approach, and in any case is unlikely to be tried in a democratic polity. Restrictions imposed on access to modern contraceptive technology are not politically acceptable; they would be also certain to prove a failure. This leaves the traditional levers of social policy: dispensing material incentives and disincentives so as to increase the willingness of couples to have children. Such incentives can be engineered by the government through fiscal measures, such as differential taxation favoring families with children, and/or through services in kind, such as free or subsidized day-care centers for pre-school children provided by public programs, and also by mandates imposed on the private sector. Creation of a generally-child-friendly environment - maintenance of public playgrounds and 
extension of lower public transport prices (often routinely granted to older people) to children and similar measures - is a logical part of such pronatalist measures. This approach was tried in the interwar years, but, as noted above, with at best limited success, which, however, could be attributed to insufficient funding and scale. In the most recent decades low fertility countries once again introduced fertility-supporting policies; in fact, with the steadily expanding welfare state, they were often upgraded and their scope, too, was extended. However, they were no longer justified by a "pronatalist" intent but were adopted as a logical part of the more encompassing frame of family and general welfare policy. The new label partly reflects a political-ideological preference, but in part also the fact that some distinctive features of pronatalism — such as rewards that differentially favored large families, and non-means-tested or even regressive allocation of family and child benefits - are generally absent since considered politically no longer acceptable.

Although the redistributive policies of the contemporary welfare state are biased in favor of the elderly and the poor, government-organized transfers to parents of children, or to children directly (including publicly financed or subsidized education often beyond the secondary school level, which lessen the cost of children to parents), are substantial in all low-fertility countries. Indeed, it is typically assumed that existing family and welfare policies sustain fertility above a level that would ensue in their absence. Accordingly, making these policies more generoussocializing an even larger share of child costs - is often seen as a means toward achieving a higher level of fertility, whether as an outright policy objective or as an unintended but expected byproduct. Ambitious deployment of such measures, however, is difficult, given the fiscal constraints of already overcommitted welfare states. And more to the point, the net effect of family-friendly redistribution of incomes and provision of services in kind is uncertain. Redistribution involves administrative costs and inefficiencies and beyond a low limit is bound to generate dissatisfaction. When income levels and parity distributions are compressed, redistribution becomes dominantly churning: people left alone could pay for the costs of their children but in fact pay also for other people's children and in turn other people pay it back to the donors in kind. Not only the efficiency of the arrangement is questionable but so is its positive effect on the willingness to have children. It is notable that in the US, where such schemes are distinctly less well funded than, for example, in Western Europe, fertility is, nevertheless, relatively high.

In recent decades, in modern industrial economies, participation of women in the formal labor force expanded rapidly. This tendency, reflecting market forces but also encouraged by government policy (partly as an antidote for deteriorating dependency ratios as the population becomes older), is likely to continue. Among the factors explaining the low level of fertility despite general material affluence, many observers point to the double burden on women of both raising children and working outside the home. To the extent that higher birth rates are seen to be socially desirable, the derived policy prescription is to adopt measures that make motherhood 
and women's labor force participation more compatible. The higher fertility in countries (notably in Scandinavia) where such measures are strongly applied, compared to countries (for example those in Southern Europe) where they are largely absent, suggests that enhanced compatibility (fostered through day-care services, flexible work-hours, liberal sick-leave allowances, post-birth paid time-off for mother and also the father, and similar arrangements) is an effective pronatalist policy even if motivated by other considerations. But it is far from clear whether the fertility differential so generated is high enough to bring the total fertility rate back to replacement level. Steady labor force participation of women during the childbearing years can certainly be made compatible with having one child or even two. It is likely to be far less compatible with sustaining, or even increasing, the proportion of women who have more than two children. Many career-oriented women voluntarily remain childless; many others prefer a single child. It follows that to achieve average replacement-level fertility, the proportions of such women need to be counterbalanced by high enough proportions of women who have chosen third-, fourth-, or even higher-order births. There is little indication at present that policies directed at enhanced compatibility achieve that result.

When fertility is high, as it still is in most of Africa and in many parts of West Asia, it is a safe prediction that with economic development it will eventually decline, at least to replacement level. Once fertility is lower than that, predictions of fertility become highly hazardous. European and also East Asian experience suggests that fertility has a tendency to settle below an average of two children per woman, hence a tendency toward sustained population decline. The question, to which no satisfactory answers exist, is "how far below?" "Scandinavian"-style family policies may stabilize fertility only modestly below replacement - such as around a total fertility rate of 1.8. That would imply a fairly moderate relative shortfall of births compared to deaths, and population stability in rich countries (that are attractive destinations for immigrants) with such vital rates could be fully or nearly compensated with a modest level of controlled immigration. Population aging would be then kept within relatively narrow limits, which postindustrial economies could readily adjust to. The demographic weight of such countries within the global total in the foreseeable future would continue to shrink, raising possible problems of a shifting geopolitical balance. Still, such demographic configurations and dynamics would be likely to push the day of demographic reckoning beyond the policy horizons that governments feel an obligation to be actively concerned with. Pronatalist interventions would then find not more than a marginal place on governments' policy agendas.

In contrast to the likely quiet acceptance of sub-replacement fertility by governments and by public opinion at large as long as the shortfall is modest or seen as likely to be only transitional, debates and policy conflicts concerning immigration in low fertility countries are almost certain to get more heated. The logic of economic globalization, allowing minimally impeded movement of goods and capital also calls for free international mobility of labor, hence of population. It questions the relevance and appropriateness of population policies conceived for national entities 
with essentially closed borders, that is, precluding free and possibly large-scale net immigration. But the fundamental difference between people crossing national borders permanently and goods and capital moving across such borders will be increasingly recognized and social and cultural considerations will tend to contradict purely economic arguments. The notion that whatever the social costs of immigration are, below replacement fertility must be compensated by immigrants (so as to counterbalance declining total numbers, raise aggregate fertility rates, attenuate population aging, and provide remedies for a supposed labor shortage) will be considerd by manyi $\mathrm{n}$ the native population as spurious. The resolution of the debate between these conflicting views and interests is difficult to predict. The economic argument may prevail, as it did, grosso modo, in Western Europe and in the United States in recet decades. The polar opposite would be the emergence of a broad consensus supporting an indefinite pause in mass immigration and adoption of policies that effectively enforce such a pause. The latter outcome could eventually also undermine some other tenets of economic globalization, leading to a return to a state in which large countries or contiguous assemblages of smaller countries seek a greater degree of self-sufficiency and industrial balance than present-day tendencies would seem to predict.

\section{Policies to avert population collapse: options "outside the box"}

Contrary to the benign assumptions just described, fertility levels in the lowest-fertility countries - countries with a total fertility rate of 1.5 or below-instead of creeping back toward replacement-level fertility might stabilize at that level, or even shrink further, reflecting the sum total of the decentralized and uncoordinated decisions of individuals and individual couples. Such an outcome, impervious even to heavy application of garden-variety pronatalist social policies might also foreshadow future reproductive behavior in countries in which fertility is still fairly close to replacement level. Should this happen - transition with a vengeance - it would create a qualitatively different demographic situation for which there exist no precedents in modern history. It would represent a clear threat to the continuing viability of the countries affected. Compensatory immigration flows would have to be so large as to be inconsistent with any reasonable degree of cultural and ethnic long-term continuity. Alternatively, population aging in the absence of immigration would create virtually unsolvable economic and social challenges, and, in the case of formerly powerful countries, there would be a likely drastic loss of relative geopolitical status. Yet the economic and socio-cultural forces that pushed down the births rate in the West and in Japan in the 1970s and 1980s to historically unprecedented low levels, and did so somewhat later in many other countries, may not have run their full course. Further declines, sparked, for example, by major economic disturbances or further fertilitydepressing cultural shifts cannot be dismissed as a possibility. Spontaneous homeostatic mechanisms may not come into play to save the day, or may do so too sluggishly to matter. A demographic collapse would become a real prospect. A radical rethinking of fertility policy would then become a necessity for social—and national—survival. 
In very low fertility countries a search for potentially more effective pronatalist measures than the existing armamentarium will then receive high priority on the public policy agenda. There would be need to think "outside the box," and to search for and, if politically feasible, actually apply, more effective measures.

This is a tall order, thus far largely ignored by demographers and other social scientists. More than a quarter century ago, I noted some of the types of remedies that should be considered--not with any expectation that they might lead to actual policies in the foreseeable future, but simply as matters that ought to be discussed as potential measures that some day may be needed. The remedies mentioned were borderlin-utopian and received very little attention, as did similar proposals bruited int he past. I still believe that they deserve debate and critical examination, possibly leading to actionable policies kept in reserve. I describe them very briefly below.

One of these suggested measures was not a population policy measure proper, but one whose adoption could create a more hospitable reception for effective pronatalist measures in democratically elected legislatures. It was a proposal for electoral reform, aimed at to at least partially counterbalance the now near electoral majority of the older population - itself a result of population aging, that is to say in no small measure consequent upon sustained prior low fertility. Because of that near-majority, legislative acts are disproportionately influenced by the interests of age groups with low average life expectancy, hence relatively low time horizons. As a result, even with generous allowance for statesmanship and altruism, a strong bias exists to the detriment of the young. The very young--for example those under 20 in Japan--constitute of course a completely disenfranchised group. They could, however, be granted full voting power, to be exercised by their parents or caregivers. (Mothers, for example, could vote on behalf of their minor daughters; fathers on behalf of their minor sons.) This proposal was later actually debated in the Bundestag, and more recently received serious attention in Japan. The objection, that owing to the very age-bias just noted, such a reform is doomed in the legislature is no doubt valid. Yet its advocacy still have merit as a signal calling attention to a flaw in intergenerational negotiations, as well as a symbolic recognition of the parents who are raising the future generation. Various refinements of the proposal, making the intended change more modest or else amplifying it further, can easily be envisaged. For example, in the case of a bicameral legislature, votes for representatives in the upper chamber could be weighted by the average life expectancy of the voter's age--something technically feasible in electronic voting systems.

Among other reform proposals, now directly motivated by the aim of increasing fertility, I adumbrate three.

First, compatibility of motherhood and labor force participation of both parents is a desirable goal for many couples, typically both as a matter of personal fulfillment and for economic necessity. But that goal, even under family friendly policies, tends to be inconsistent with the desire to have a large family_large not by historical measures but in its contemporary 
understanding: a family consisting of three, four, or five children. Economic considerations and consideration of children's interest is likely to bar the choice of a large family in an urbanindustrial society to all but couples in the riches segment of the income distribution. Yet there is evidence that a substantial subset of couples would chose there, four, or five children if that would not unduly disadvantage themselves and their children, either economically and socially. Family policy, which now subsidizes childbearing - first and second children - that in the large majority of cases would be born in any case reflecting parental preferences, could be reconfigured to support large families. Rearing children in such families is full time work: in the collective interest it could be so recognized by society and rewarded by pay as full time work in the formal labor force, at a level equivalent to what the caretaking person-whether the mother or the father - could command given her or his qualifications. Society may rely on responsible self-selection of couples into that category, or require screening and imposition of a degree of control over fitness for and predicted performance in that role, resembling routinely applied aptitudinal tests in the formal labor force. A variety of intermediate solutions between those two approaches could be acceptable for the general public.

Second, with population aging, support in old age becomes a growing source of anxiety in the population at large. Collective commitments, taken under conditions of a population age distribution with a more favorable ratio between those in working ages and those past the age of retirement than the ratio generated by persistent low fertility, become increasingly untenable, generating a pressure for accumulation of assets on private accounts, to be used in retirement. Having children, especially more than two children, represents a distinct disadvantage in that endeavor. Linking high individual fertility with an institutionally secure assurance for an emphatically preferential treatment in old age with respect to government-provided pension and health services could be seen both as socially just and act as a potentially potent pronatalist measure. A variety of solutions for such a linkage could be designed, recognizing not only the number of children a person or a couple had, but also the quality, reflected in the educational qualifications and the economic productivity of offspring once children enter the labor force and become taxpayers.

Third, low-fertility high-income countries have elastic access to potentially willing immigrants at least for many decades into the future. UN projections, for example, posit a net population increase by 2050 of over half a billion in India and over a billion in Africa. Yet, as was suggested above, massive net immigration that would be necessary to moderate the speed of population decline in absolute terms and lessen population aging in very low fertility countries is likely to be inconsistent with preferences in the receiving populations, as such influx could radically transform their cultural, ethnic, and even linguistic makeup and, by many of history's lessons, become the source of severe political conflicts. But restricting immigration in the context of very low fertility then reimposes the need for search for measures to increase the birth rate of the native population. One argument favoring immigration is the claim that certain tasks in the labor 
force necessary for the functioning of the economy, and especially of social services within it, cannot be secured from the use of the native labor force. That claim is likely to be weak in a well-functioning market economy, and under conditions of a not over-solicitous welfare state, but may nevertheless have some validity. There is a long historical tradition, once accepted and considered honorable but now discarded in most affluent countries, of compulsory military service for young males. A society that wishes to restrict immigration, or screen immigrants in favor of a demographically not-significant highly qualified immigrant flow only, may then contemplate reintroduction of an obligatory civilian service corps, now embracing both sexes, as part of the duties required from all citizens in a particular stage of their lives. There is indeed recurrent discussion of creating such a civilian corps in many countries. On a purely voluntary basis, it is unlikely that such plans could come to fruition beyond marginal significance. Current ideological attitudes notwithstanding, striving for national viability and indeed long term national survival may yet create conditions where, on the analogy of compulsory military service of past times, a civilian service corps could be contemplated and socially accepted and made in fact largely voluntary even if service in it is formally enforced. In modern conditions, the age of entry for a service extending perhaps for a length of two to there years, would be logically somewhat flexibly chosen by the participants, but the minimum age allowed would be appreciably higher than once was the case in military service - past the age when contemporary formal education is generally completed, that is, in the early twenties. The only significant exemption from such a service would be a service equally valued by the community: maternity and paternity. Even if opting for such an exemption would be taken only by a minority, reappearance of early parenthood would represent a break with current trends and arguably set into motion behavioral repercussions appreciably counteracting socially harmful demographic developments.

Such proposition may seem still utopian today, especially in the ideological environment of the European Union and the United States. They may not do so in a not too remote future. At least their discussion, and discussions of similar or even farther-reaching reform proposals, may well attract demographers and policy makers even today.

\section{References}

Birdsall, Nancy, Alana C. Kelley, and Steven Sinding. 2001. Population Matters: Demographic Change, Economic Growth, and Poverty in the Developing World. Oxford: Oxford University Press. 
Bloom, David E, and David Canning. 2008. “Global demographic change: Dimensions and economic significance," in Alexia Prskawetz, David E. Bloom, and Wolfgang Lutz, Population Aging, Human Capital Accumulation, and Productivity Growth. Supplement to Vol. 34 of Population and Development Review, 17-51.

Bongaarts, John. 1997. "The role of family planning programmes in contemporary fertility transition," in G. Jones, R. Douglas, J.C. Caldwell, and R. D'Souza (eds.), The Continuing Demographic Transition. Oxford: Clarendon Press.

Cantillon, Richard. 2010 [1755]. An Essay on Economic Theory. (Tr. of Essai sur la Nature du Commerce en Géneral by Chantal Saucier). Auburn, AL: LvMI.

Carr-Saunders, A.M. 1922. The Population Problem: A Study in Human Evolution. Oxford: Clarendon Press.

Cassen, Robert, and contributors. 1994. Population and Development: Old Debates, New Conclusions. New Brunswick, NJ: Transaction Publishers.

Coale, Ansley J., and Edgar M. Hoover. 1958. Population Growth and Economic Development in Low-Income Countries. Princeton, NJ: Princeton University Press.

Connelly, Matthew. 2008. Fatal Misconception: The Struggle to Control World Population. Cambridge: Harvard University Press.

Daly, Herman E. 2008. "Growth and development: Critique of a credo." Population and Development Review, 34(3): 511-518.

Demeny, Paul. 1987. "Pronatalist policies in low-fertility countries: Patterns, performance, and prospects," in. Kingsley Davis, Mikhail S. Bernstam, and Rita-Ricardo Campbell, eds., BelowReplacement Fertility in Industrial Societies: Causes, Consequences, Policies. Cambridge: Cambridge University Press, pp. 335-358.

-------. "Replacement-level fertility: The implausible end pointy of the demographic transition," in The Continuing Demographic Transition, G.W. Jones et al., eds, Clarendon Press, Oxford, 1997, pp. 94-110.

Donaldson, Peter J. 1990. Nature Against Us: The United States and the World Population Crisis, 1965-1980. Chapel Hill, NC: University of North Carolina Press.

Dumont, Arsène. 1990 [1890]. Dépopulation et Civilisation: Étude Démographique. Paris: Economica. 
Easterlin, Richard. 1997. Growth Triumphant: The Twenty-First Century in Historical Perspective. Ann Arbor: University of Michigan Press.

Ehrlich, Paul R., and Ann H. Ehrlich. 2004. One with Niniveh: Politics, Consumption, and the Human Future. Washington, DC.: Island Press.

Greenhalgh, Susan. 2008. Just One Child: Science and Policy in Deng's China. Berkeley: University of California Press.

Keynes, John Maynard. 1937. "Some economic consequences of a declining population." Eugenics Review. 29(1): 13-17.

Landry, Adolphe. 1934. La Révolution Démographique. Paris: Sirey.

Lloyd, W. F. 1968 [1833] "Two lectures on the checks to population," in Lectures on Population, Value, Poor Laws and Rent. New York: Augustus M. Kelley.

Mahler, Halfdan. 1992. "Our next forty years." People 19: 3-6.

Malthus, T. R. 1820. Principles of Political Economy. London: John Murray.

McDonald, Peter. 2006. "Low fertility and the state: The efficacy of policy." Population and Development Review 32(3): 485-510.

McEvedy, Colin, and Richard Jones. 1978. Atlas of World Population History. Penguin Books. McNicoll, Geoffrey. 2006. "Policy lessons of the East Asian demographic transition." Population and Development Review 32(1): 1-25.

Myrdal, Alva. 1941. Nation and Family: The Sweedish Experiment in Democratic Family and Population Policy. London: Routledge.

Notestein, Frank W. 1950. "The population of the world in the year 2000." Journal of the American Statistical Association. 45 (251).

Pecchi, Lorenzo, and Gustavo Piga, eds. 2008. Revisiting Keynes: Economic Possibilities for Our Grandchildren. Boston: MIT Press.

Piotrow, Phillis Tyson. 1973. World Population Crisis: The United States Response. New York: Praeger Publishers.

Pritchett, Lant H. 1994. "Desired fertility and the impact of population policies." Population and Development Review 20(1): 1-55. 
Spengler, Oswald. 1956 [1922]. The Decline of the West. (Tr. by C. F. Atkinson.) Vol. 2. New York: Alfred A. Knopf.

United Nations. 2001. Replacement Migration: Is It a Solution to Declining and Ageing Populations? New York: United Nations.

-------. 2009. World Population Prospects: The 2008 Revision. Volume I: Comprehensive Tables. New York: United Nations. 